satisfactory in its effects. There was no inflammatory reaction and the coloboma remained free from exudate. The tension sank to normal and the patient was able to count fingers and to get about well even in places that she did not know.

Comments. - The presence of an intraocular growth was not suspected until the eye was bisected. There would seem to be little doubt that the severe irido-cyclitis was due to toxins liberated by the necrosing action of the sarcoma. The rapid improvement which took place in the sympathizing eye after the removal of the exciting eye strongly supports the idea that the inflammation was sympathetic in type. On the other hand the true Fuchs inflammation was not present nor were there any cells in the aqueous of either eye. It is obvious, therefore, that the case was not one of true sympathetic ophthalmitis, although it was a sympathetic inflammation.

The eye eventually became perfectly white, and the astonishing acuity of $6 / 12$ was gained. The patient has now returned to her work as an assistant in a draper's shop.

\title{
CASE OF EMPHYSEMA OF THE CONJUNCTIVA
}

BY

LaURa M. LigerTwood, F.R.C.S.E.

CLINICAL TUTOR, EYE DEPARTMENT, ROYAL INFIRMARY, EDINBURGH

THE following accident is of such unusual occurrence as to merit special attention,

On June 5, 1926, W.B., male, aged 40 years, reported at the Eye Department of the Royal Infirmary, Edinburgh, and gave the following history.

Patient stated that he was employed as an engraver in a granite yard and that he worked with a pneumatic driller. The air which drives these pneumatic drills is compressed by an engine, led through the yard in large iron pipes and smaller rubber tubes and when emerging from the nozzle of the tube has a pressure of $70 \mathrm{lbs}$. per square inch. It is the custom of the men when they have finished work to blow the dust out of their clothes by means of the compressed air. On the date in question, W.B. took hold of the flexible rubber tube about two feet from its free end and turned on the air, the pressure of which caused the tube to fly backward and pass in close proximity to the face actually touching the skin over the right maxilla. The eye received the full force of the $70 \mathrm{lbs}$. pressure. 
On examination the conjunctiva was raised in several large and very many small bullae which were filled with air and presented an appearance somewhat similar to chemosis of conjunctiva being, however, more loculated. On palpation the typical crackling feeling of emphysema was experienced. The conjunctiva had not much injection and there was no obvious tear to be seen. The pupil was slightly dilated-fundus normal- lens clear-no refractive error

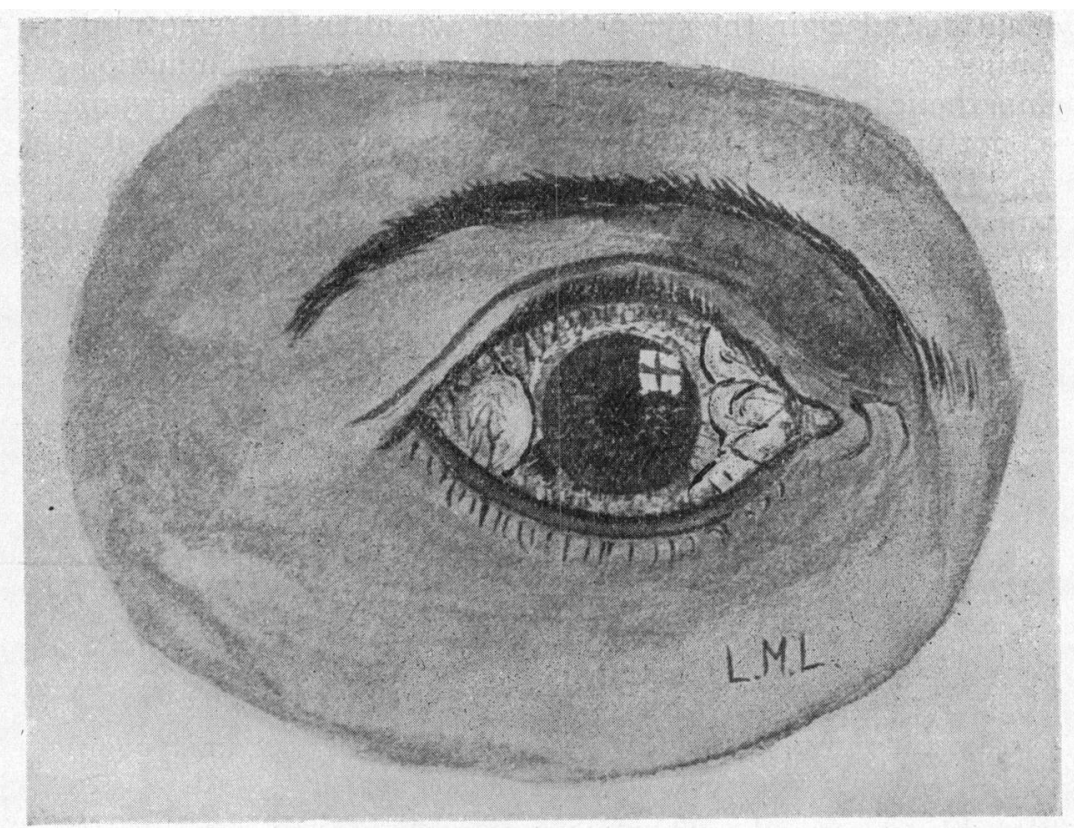

and vision 6/9. The vision in the left eye was 6/4. The accompanying photograph of an original drawing shows the condition on the afternoon of the same day.

On June 7, 1926, there was considerably less air present.

On June 8,1926 , there were only a few air-bells above and to the temporal side. Examination in dark room showed no abnormality and vision on this day was $6 / 4$ the same as the other eye.

Patient was last seen on June 11,1926, when there was no trace of the accident left save a very slight conjunctival injection. He was then allowed to return to work.

I have not been able to find a report of a similar case in the literature.

I am indebted to Dr. J. V. Paterson, Eye Department, Royal Infirmary of Edinburgh, for permission to publish these notes of the case. 